\title{
Neighbourhood ethnic composition and diet among Mexican-Americans
}

\author{
Carlos A Reyes-Ortiz ${ }^{1, *}$, Hyunsu Ju², Karl Eschbach ${ }^{3}$, Yong-Fang Kuo ${ }^{2}$ and \\ James S Goodwin ${ }^{2}$ \\ ${ }^{1}$ School of Public Health, University of North Texas Health Science Center, EAD-71 1B, 3500 Camp Bowie \\ Boulevard, Fort Worth, TX 76107-2699, USA: ${ }^{2}$ Sealy Center on Aging, University of Texas Medical Branch, \\ 301 University Blvd, Galveston, TX 77555-0460, USA: ${ }^{3}$ Institute for Demographic and Socioeconomic Research, \\ University of Texas at San Antonio, One UTSA Circle, San Antonio, TX 78249-0704, USA
}

Submitted 24 October 2007: Accepted 18 December 2008: First published online 3 March 2009

\begin{abstract}
Objectives: We explore the association between a neighbourhood's ethnic composition and the foods and nutrients consumed by Mexican-Americans.

Design: Cross-sectional survey of a large national sample, from the Third National Health and Nutrition Examination Survey (1988-94), was linked to the 1990 Census. The outcomes were food frequencies and serum levels of micronutrients. The variable of interest was percentage of Mexican-Americans at the census tract level. Setting: United States.

Subjects: A total of 5306 Mexican-American men and women aged 17-90 years. Results: Increased percentage of Mexican-Americans at the census tract level was associated with less consumption of fruits, carrots, spinach/greens and broccoli and with lower serum levels of Se, lycopene, $\alpha$-carotene, vitamin $\mathrm{C}$ and folate. By contrast, increased percentage of Mexican-Americans at the census tract level was associated with more consumption of corn, tomatoes, hot red chilli peppers and legumes such as beans, lentils or chickpeas.

Conclusions: An increased percentage of Mexican-Americans at the census tract level was associated with less consumption of selective foods (e.g. some fruits, broccoli) and low levels of serum Se or vitamin C, but it was associated with more consumption of other foods (e.g. legumes, tomatoes, corn products) that may have positive effects on health in this population.
\end{abstract}

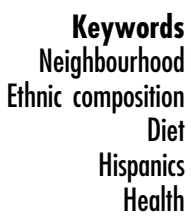

Assimilation and acculturation have long been recognized as important though complex correlates of change in health risk profiles of immigrants and the resulting ethnic populations ${ }^{(1,2)}$. The standard model that dominates research on acculturation and health suggests that new immigrant populations typically have a set of risk profiles that are distinctive from those of the population of the host society in which they have settled. These differences may reflect a combination of influences, including the maintenance of culturally distinctive behaviours characteristic of the country of origin; the distinctive influences of the immigration experience itself, including disruption of personal networks and exposure to discrimination; and the correlation of the decision to migrate across national boundaries with distinctive personal characteristics. Time spent in the host society - measured in years, and sometimes generations, among the descendents of immigrants - tends to erode these differences. Social epidemiologists frequently turn to the variables of time and, where relevant, linguistic change - the adoption of the language of the destination society - as correlates of changes in social and behavioural risk profiles away from those characteristic of the immigrant group itself, and towards those characteristic of segments of the broader population of the country of destination ${ }^{(1,3-5)}$.

Recently, increased attention has been given in the social epidemiology literature to the influence of the socialspatial context of health. In particular, a growing literature investigates variation in local social environments with respect to variables such as quality of food supply, local modelling of healthy diets and personal habits, stressfulness of daily living and encouragement of physical activity $^{(6-10)}$. In the context of the social scientific study of immigrant incorporation, this emphasis is concordant with a well-documented relationship linking ethnic residential enclaves with the maintenance and intergenerational transmission of ethnic-specific cultures ${ }^{(11-13)}$. Drawing on these broader social science research findings, epidemiologists have investigated the hypothesis that ethnic concentration of immigrant-derived populations in neighbourhoods is 
associated with the maintenance of group-specific social behavioural practices that influence health outcomes.

The Mexican-American population of the USA provides a particularly noteworthy case for the investigation of the effects of residential concentration on health. Compared with non-Hispanic whites, Mexican-Americans have lower mortality rates from all causes, and from leading causes including CVD and cancers at most common sites ${ }^{(13-18)}$. Mexican-American mortality rates are consistently reported to be lower for immigrants than they are for MexicanAmericans born in the USA ${ }^{(13,15,17-19)}$. That mortality rates are lower for a Mexican-American population that is on average socio-economically disadvantaged has been described as an epidemiological paradox ${ }^{(20,21)}$.

One of the leading hypotheses about the better than expected health and mortality outcomes for MexicanAmericans, as well as the apparently poorer outcomes for US-born Mexican-Americans compared with immigrants from Mexico, points to protective aspects of healthrelated behaviours among immigrants, including healthier diets, lower rates of smoking, substance and alcohol use, and higher rates of physical activity ${ }^{(13,16,21,22)}$. Indeed, studies of acculturation have documented a relationship between acculturation and less healthy lifestyles in the Mexican origin population, although effects of acculturation are not entirely negative. Notably, both healthcare access and use of screening improves with greater acculturation.

A small but growing number of studies have examined the hypothesis that a high concentration of Mexican populations in residential communities is associated with better health outcomes. To date, results have been mixed. Some studies report evidence of lower mortality, lower chronic disease morbidity, better mental health and higher self-rated health ${ }^{(23-31)}$. Others report weak, contradictory or null results ${ }^{(13,32,33)}$.

In the present study we investigate the relationship between ethnic residential concentration of MexicanAmericans and dietary intake. Specifically, we investigate the hypothesis that there is a strong relationship between ethnic concentration, e.g. residence in a barrio community, and types of foods consumed. This hypothesis has a high degree of plausibility, because a high level of ethnic concentration in a local community creates a context for the supply of ethnic-specific food products and for the modelling of dietary practices. The Mexican-American population lives in very diverse residential settings, ranging from homogeneous ethnic environments in nearborder areas in the south-west, to neighbourhoods throughout the USA where they are highly integrated with non-Hispanics. Do dietary practices among MexicanAmericans in different neighbourhood settings differ in ways that suggest that integration with other groups leads to deterioration of dietary practices that help explain the increasing rates of chronic disease prevalence among more acculturated Hispanics?

\section{Methods}

\section{Data source}

The Third National Health and Nutrition Examination Survey (NHANES III), a large US survey conducted from 1988 to 1994 , is a major source of information on the nutritional and health status of the US population aged 2 months or more ${ }^{(34)}$. The strength of this survey is that it used the same stratified multistage probability design as previous National Health and Nutrition Examination Surveys ${ }^{(34)}$. Weights indicating the probability of being sampled were assigned to each respondent, enabling results to represent the US population for each group. Mexican-Americans were over-sampled to produce statistically reliable health estimates for the largest ethnic minority subgroup in the USA. The data were collected via standardized questionnaires administered by health professionals at participants' homes; standardized medical examinations by physicians, medical technicians and other health professionals at the National Health and Nutrition Examination Survey mobile examination centres (MEC); and laboratory tests on whole blood and sera. Interviews were conducted in English and Spanish after informed consents were obtained at the initial home interview. The interviewer gave each person selected for the survey a brochure which described the survey procedures using a question-and-answer format and included photographs of people being examined in the MEC rooms. The final page of the brochure was a paper that required the signature of each participant 18 years of age and older ${ }^{(34,35)}$. Response rates were high, $78 \%$ completed both the home interview and the medical examination. To get the percentage of Mexican-Americans at the census tract level, the NHANES III was merged with the 1990 US Census data. To avoid any potential identification of subjects, the merge of the NHANES III public database ${ }^{(36)}$ with neighbourhood data (US Census Bureau, 1990) ${ }^{(37)}$ was made by the National Center for Health Statistics (NCHS) Research Data Center (Hyattsville, MD, USA). We sent the statistical models needed for our analyses and the NCHS remote system sent us back the results. The study protocol was approved by the University of Texas Medical Branch Institutional Review Board.

\section{Study sample}

The sample for our analyses included 5306 MexicanAmerican men and women aged 17-90 years who completed both the home questionnaire and medical examination.

\section{Measurements}

The outcomes were food frequencies and serum levels of nutrients.

Food frequencies were assessed by a 1-month qualitative $\mathrm{FFQ}^{(38,39)}$. The NHANES III nutrient database for individual foods is derived from the US Department of 
Agriculture's Survey Nutrient Database ${ }^{(39,40)}$. To ensure the accuracy of the nutrient contents of foods, substantial care was taken to include a wide variety of traditional Mexican foods (e.g. red chilli peppers) ${ }^{(41,42)}$. The FFQ, administered during the household interview, was used to ask respondents about the average number of times foods were eaten during the 1-month period preceding the interview date. Frequencies of consumption of foods from the following food groups were ascertained: fruits, vegetables, grains and legumes.

Serum levels of nutrients have been shown to correlate well with dietary intake of respective nutrients ${ }^{(43)}$. The micronutrients examined included those considered to be of potential public health significance and thought to decrease the risk of cancer or CVD ${ }^{(44-48)}$. Serum levels of the following nutrients were obtained: lycopene, Se, vitamin E, vitamin $\mathrm{D}$, vitamin $\mathrm{A}$, vitamin $\mathrm{C}$, vitamin $\mathrm{B}_{12}$, folate, $\alpha$-carotene and $\beta$-cryptoxanthin. Serum levels of nutrients were determined by nutritional biochemistry. MEC collected blood samples and used the following assay or instrumentation methods for laboratory assessments: 'Quantaphase Folate' RIA Kit (Bio-Rad Laboratories, Hercules, CA, USA) for folate; HPLC (Waters Corporation, Milford, MA, USA) for vitamins A, C and E and carotenoids (lycopene, $\alpha$-carotene, $\beta$-cryptoxanthin); INCSTAR $25-\mathrm{OH}-\mathrm{D}$ RIA Kit (INCSTAR, Stillwater, MN, USA) for vitamin D (25-hydroxyvitamin $\mathrm{D}_{3}$ ); ${ }^{125} \mathrm{I}$-folic $/{ }^{57} \mathrm{Co}-\mathrm{B}-12$ for vitamin $\mathrm{B}_{12}$; and graphite furnace atomic absorption using Perkin-Elmer model 3030 and 5100 instruments (Perkin-Elmer Co., Norwalk, CT, USA) for $\mathrm{Se}^{(34)}$.

A measure of contextual acculturation, the percentage of Mexican-Americans at the census tract level (a higher percentage indicates more isolation or less integration with other ethnic groups) ${ }^{(25)}$ was used as a continuous variable. Other variables were age (years, used as a continuous variable) and gender (male and female).

\section{Statistical analyses}

All statistical analyses were carried out using the statistical software packages SAS for Windows version $9 \cdot 1$ (SAS Institute, Inc., Cary, NC, USA) and SUDAAN version $7 \cdot 11$ (Research Triangle Institute, Research Triangle Park, NC, USA). All analyses incorporated sampling weights that adjusted for unequal probabilities of selection. Because of the complex survey design used in NHANES III, traditional methods of statistical analysis based on the assumption of a simple random sample may not be reliable. Sample weights are needed to produce correct estimates of population quantities. Other aspects of the sample design (e.g. PSU (primary sampling units) pairings) should be taken into account to obtain correct standard errors and significance levels for hypothesis testing ${ }^{(49,50)}$. With continuous outcome variables, frequency of foods (e.g. cereals, tomatoes) or serum levels of nutrients (e.g. Se, lycopene), we used age- and genderadjusted linear regression analyses (REGRESS procedure) to examine the independent association of the percentage of Mexican-Americans at the census tract level with food frequencies and serum levels of nutrients.

\section{Results}

The study population comprised 2682 Mexican-American men $(50 \cdot 6 \%)$ and 2624 women $(49 \cdot 4 \%) ; 35 \%$ of subjects were aged $17-29$ years, $29 \cdot 2 \%$ were aged $30-44$ years, $13 \cdot 5 \%$ were aged $45-59$ years, $17 \cdot 5 \%$ were aged $60-74$ years and $4 \cdot 8 \%$ were 75 years of age and older. Age group distributions did not differ by gender. Eighty-eight per cent of subjects came from three of the four US-Mexico border states: California, Texas and Arizona. These states correspond to the south-west area of the USA where the majority of Mexican-Americans reside.

Table 1 shows the multivariate linear regression analyses for the relationship between consumption of specific foods (more detailed description is provided in the table) and percentage of Mexican-Americans at the census tract level. It shows that increased percentage of Mexican-Americans in the neighbourhood was associated with less consumption of melons (unstandardized beta coefficient $(b)=-1 \cdot 21$, SE $0.52, P=0 \cdot 0266)$, any other fruits (e.g. apples, bananas; $b=-4.57$, SE 1.34, $P=0 \cdot 0017)$, carrots $(b=-1 \cdot 61$, SE $0 \cdot 70, \quad P=0 \cdot 0273)$, spinach/greens $(b=-1 \cdot 17$, SE $0 \cdot 27, \quad P=0 \cdot 0001)$ and broccoli $(b=-1 \cdot 84$, se $0 \cdot 5, P<0 \cdot 0001)$. On the other hand, increased percentage of Mexican-Americans in the neighbourhood was associated with more consumption of the group of fruits that included peaches, nectarines, apricots, guava, mango and papaya $(b=0 \cdot 32$, se 0.68 , $P=0 \cdot 63)$. Although this association did not reach statistical significance, it suggests that these fruits - especially the traditional mango and papaya - may be important diet components of high-density Mexican-American neighbourhoods. By contrast, increased percentage of Mexican-Americans in the neighbourhood was associated with more consumption of corn products $(b=11 \cdot 12$, SE $2 \cdot 98, P=0 \cdot 0006)$, flour tortillas $(b=7 \cdot 17$, SE $2 \cdot 63$, $P=0 \cdot 0097)$, tomatoes $(b=2 \cdot 76$, sE $0 \cdot 94, P=0 \cdot 0060)$, hot red chilli peppers $(b=4 \cdot 05$, SE $1 \cdot 48, P=0 \cdot 0097)$ and legumes such as beans, lentils or chickpeas/garbanzos ( $b=11 \cdot 56$, SE $1 \cdot 81, P<0 \cdot 0001)$.

Table 2 shows the multivariate linear regression analyses for the relationship between serum levels of nutrients and percentage of Mexican-Americans at the census tract level. It shows that increased percentage of MexicanAmericans at the census tract level was associated with lower levels of lycopene $(b=-3 \cdot 77$, se $0 \cdot 62, P<0 \cdot 0001)$, Se $(b=-4 \cdot 99$, sE $1 \cdot 55, P=0 \cdot 0033)$, vitamin C $(b=-0 \cdot 10$, SE $0 \cdot 03, P=0 \cdot 0025)$ and folate $(b=-0 \cdot 88$, SE $0 \cdot 33$, $P=0 \cdot 0117$ ). Increased percentage of Mexican-Americans at the census tract level was also associated with higher levels of $\beta$-cryptoxanthin $(b=1 \cdot 53$, sE $1 \cdot 18, P=0 \cdot 20)$ and 
Table 1 Multivariate analysis results ${ }^{*}$ for frequency of foods as a function of the percentage of Mexican-Americans at the census tract level: outcome data in Mexican-American men and women ( $n$ 5306) were obtained from the Third National Health and Nutrition Examination Survey (1988-94) and linked to the 1990 Census

\begin{tabular}{|c|c|c|c|}
\hline \multirow[b]{2}{*}{ Outcomes (times/month) } & \multicolumn{2}{|c|}{$\begin{array}{l}\text { Percentage of Mexican-Americans a } \\
\text { census tract level (continuous) }\end{array}$} & \multirow[b]{2}{*}{$P$} \\
\hline & $b$ & SE & \\
\hline Cereals: all bran, etc. & -0.27 & $0 \cdot 36$ & 0.46 \\
\hline Spaghetti/pasta/tomato sauce & -0.87 & 0.98 & 0.38 \\
\hline Corn bread, muffins and tortillas & $11 \cdot 12$ & $2 \cdot 98$ & 0.0006 \\
\hline Flour tortillas & $7 \cdot 17$ & $2 \cdot 63$ & 0.0097 \\
\hline Rice & $-1 \cdot 34$ & $0 \cdot 82$ & $0 \cdot 11$ \\
\hline Citrus fruits: oranges, grapefruits and tangerines & -0.39 & $1 \cdot 34$ & $0 \cdot 77$ \\
\hline Melons: cantaloupe, honeydew and watermelon & $-1 \cdot 21$ & 0.52 & 0.0266 \\
\hline Peaches, nectarines, apricots, guava, mango and papaya & 0.32 & 0.68 & 0.63 \\
\hline Any other fruits: apples, bananas, pears, berries, cherries, grapes, plums and strawberries & $-4 \cdot 57$ & $1 \cdot 34$ & 0.0017 \\
\hline Carrots and vegetable mixtures containing carrots & $-1 \cdot 61$ & $0 \cdot 70$ & 0.0273 \\
\hline Spinach, greens, collards and kale & $-1 \cdot 17$ & $0 \cdot 27$ & 0.0001 \\
\hline Broccoli & $-1 \cdot 84$ & 0.35 & $<0.0001$ \\
\hline Brussels sprouts/cauliflower & $-0 \cdot 28$ & 0.42 & 0.51 \\
\hline Tomatoes & $2 \cdot 76$ & 0.94 & 0.0060 \\
\hline Hot red chilli peppers & $4 \cdot 05$ & $1 \cdot 48$ & 0.0097 \\
\hline Other peppers (green, red, yellow) & 0.66 & $1 \cdot 13$ & 0.56 \\
\hline Beans (pinto, refried, black and baked), lentils, chickpeas or garbanzos & $11 \cdot 56$ & $1 \cdot 81$ & $<0.0001$ \\
\hline
\end{tabular}

$b$, unstandardized beta coefficient; SE, standard error of the beta coefficient.

${ }^{*}$ Adjusted for age and gender.

Table 2 Multivariate analysis results* for serum levels of nutrients as a function of the percentage of MexicanAmericans at the census tract level: outcome data on Mexican-American men and women ( $n 5306)$ were obtained from the Third National Health and Nutrition Examination Survey (1988-94) and linked to the 1990 Census

\begin{tabular}{|c|c|c|c|}
\hline \multirow[b]{2}{*}{ Outcome (serum level) } & \multicolumn{2}{|c|}{ Percentage of Mexican-Americans at census tract level (continuous) } & \multirow[b]{2}{*}{$P$} \\
\hline & $b$ & SE & \\
\hline Lycopene (ug/dl) & $-3 \cdot 77$ & 0.62 & $<0.0001$ \\
\hline Selenium (ng/ml) & -4.99 & $1 \cdot 55$ & 0.0033 \\
\hline Vitamin E (ug/dl) & $-22 \cdot 61$ & $28 \cdot 12$ & 0.43 \\
\hline Vitamin D (ng/ml) & $-0 \cdot 23$ & $1 \cdot 23$ & 0.85 \\
\hline Vitamin A ( $\mu \mathrm{g} / \mathrm{dl})$ & $-2 \cdot 00$ & 1.01 & 0.0560 \\
\hline Vitamin C (mg/dl) & $-0 \cdot 10$ & 0.03 & 0.0025 \\
\hline Folate (ng/ml) & $-0 \cdot 88$ & 0.33 & 0.0117 \\
\hline Vitamin $B_{12}(p g / m l)$ & $191 \cdot 2$ & $179 \cdot 1$ & 0.32 \\
\hline$\alpha$-Carotene $(\mu \mathrm{g} / \mathrm{dl})$ & -0.73 & 0.35 & 0.0427 \\
\hline$\beta$-Cryptoxanthin $(\mu \mathrm{g} / \mathrm{dl})$ & $1 \cdot 53$ & $1 \cdot 18$ & $0 \cdot 20$ \\
\hline
\end{tabular}

$b$, unstandardized beta coefficient; SE, standard error of the beta coefficient.

${ }^{*}$ Adjusted for age and gender.

vitamin $\mathrm{B}_{12}(b=191 \cdot 2$, se $179 \cdot 1, P=0 \cdot 32)$ but did not reach statistical significance.

\section{Discussion}

In the present study, we focused on spatial aspects of assimilation in relation to dietary quality using data from a geo-coded NHANES III data set, where the characteristics of tract populations from the 1990 census were attached to individual records to investigate the relationship between the social characteristics of tract populations and nutrient profiles measured through self-reported dietary recalls and measurement of serum nutrients. The emphasis on spatial characteristics of residential communities as a possible correlate of changes in nutrition is consistent with a very old social science research finding that residential concentration of immigrant and ethnic populations serves to maintain ethnic-specific cultural patterns ${ }^{(11,12)}$. It is also consistent with a recent research stream in epidemiology that investigates the socio-economic characteristics of neighbourhoods of residence in relation to health-related behaviours and health outcomes $^{(51)}$. It also identifies a variable with a broad range among Mexican-Americans, who are distributed across a broad spectrum of residential environments, ranging from a high degree of ethnic segregation in the border region of Texas, to full integration with non-Hispanics in urban and suburban communities throughout the $\mathrm{USA}^{(52)}$.

Dietary patterns including vegetables and fruits have been associated with lower risk of all-cause mortality using data from the National Health Interview Surveys ${ }^{(53)}$ and the 
Breast Cancer Detection Demonstration Project ${ }^{(54)}$; and with lower risk for CVD using data from the Physicians' Health Study ${ }^{(55)}$, the Nurses' Health Study ${ }^{(56,57)}$, the Health Professionals' Follow-up Study ${ }^{(57,58)}$ and the Framingham Nutrition Studies ${ }^{(59)}$. In addition, case-control and cohort studies showed that vegetables and fruits have been associated with reduction in the risk of some cancers including mouth and pharynx, oesophagus, stomach, colon-rectum, larynx, lung, breast (vegetables only), ovary (vegetables only), bladder (fruits only) and kidney ${ }^{(60-62)}$.

However, higher concentrations of Mexican-Americans in a neighbourhood are correlated with poverty and disadvantage; therefore, the pattern of low consumption of some fruits (e.g. cherries, berries) and some vegetables (e.g. broccoli) in our study may reflect unaffordable costs for foods or lower availability in a neighbourhood food environment ${ }^{(26)}$. Indeed, in another study, Bodor et al. ${ }^{(63)}$ reported that greater fresh vegetable availability within 100 metres of residences was a positive predictor of vegetable intake.

Studies of health and mortality patterns of MexicanAmericans living in the USA have previously reported greater longevity ${ }^{(13,17-19)}$ and lower biological risk profiles ${ }^{(64)}$ for Mexican-American immigrants residing in the USA compared with non-Hispanic whites and US-born Mexican-Americans. US-born Mexican-Americans appear to have mortality rates and biological risk profiles similar to or not much worse than those of non-Hispanic whites, which some commentators appear to ascribe as unexpected because of the much lower average socio-economic status of US-born Mexican-Americans compared with non-Hispanic whites.

The explanation of the lower mortality and better than expected biological risk profiles of Mexican-Americans remains a matter of investigation and debate. Recent work has substantially removed data quality concerns as the principal explanation of these patterns ${ }^{(19,65,66)}$. A second hypothesis suggests that the greater propensity to immigrate of persons with better health may play a leading role, although direct evidence for this hypothesis remains weak. A third set of explanations points to healthier socio-cultural risk profiles as a contributing element. More nutritious diets for immigrants, lower rates of smoking and substance use, and stronger social support, are frequently hypothesized to contribute to the Mexican-American mortality advantage. These hypotheses are concordant with evidence showing decreases in the quality of diets and health-related behaviours with increasing time and generation in the $\operatorname{USA}^{(1,39,67,68)}$.

On the other hand, high consumption of legumes (especially beans) and hot red chilli peppers may reflect cultural preferences and more affordable foods for this Mexican-American population ${ }^{(41,42)}$. It has been reported that dietary patterns are different and generally less healthy for US-born compared with immigrant Mexican-Americans. Dixon et al. ${ }^{(41)}$ reported that US-born Mexican-Americans consumed significantly more fat and less fibre and vitamins, and were less likely to meet dietary guidelines than were immigrant Mexican-Americans. Also, Guendelman and Abrams $^{(67)}$ reported that first-generation Mexican-American women had higher average intakes of protein, vitamins A and $\mathrm{C}$, folic acid and $\mathrm{Ca}$ than second-generation Mexican women, whose nutrient intake resembles that of white nonHispanic women. Other studies have shown that acculturation to the US culture among Mexican-Americans was associated with increased dietary fat and sugar along with higher waist circumference and abdominal obesity ${ }^{(41,69-71)}$. A potential explanation on how acculturation affects diet among Mexican-Americans is related to a higher food store availability and consumption of fast food in inner-city neighbourhoods ${ }^{(72,73)}$. The consumption of these other foods may influence the selection of a healthier diet profile in our study population of Mexican-Americans.

So the question we asked was whether there was evidence of dietary advantages in more rather than less ethnically homogeneous Mexican-American communities that could help explain lower rates of incidence and mortality for some chronic diseases for Mexican-Americans as a population group. Therefore, consumption of higher amounts of legumes (beans, lentils or chickpeas) may protect the health of a population with high concentration of Mexican-Americans in the neighbourhood. Indeed, consumption of higher amounts of legumes may have a protective effect against cancer. Kolonel et al. ${ }^{(74)}$ reported that intake of legumes (whether total legumes, soya foods specifically, or other legumes) was inversely related to prostate cancer risk. Also, Correa ${ }^{(75)}$ examined data from forty-one countries and found a significant inverse correlation between bean consumption and mortality due to prostate, breast and colon cancer. In other human or animal studies, high consumption of dry beans has been associated with lower rates of myocardial infarction among Costa Ricans or fewer colon adenocarcinomas among rats ${ }^{(76,77)}$. These findings may be part of the explanation why those Mexican-Americans living in neighbourhoods with a high concentration of MexicanAmericans exhibit lower cancer incidence or lower overall mortality $^{(25,26)}$. In Mexico, common beans are the second source of protein, carbohydrates, vitamins and minerals after corn ${ }^{(78,79)}$. Beans contain complex carbohydrates and are rich in $\mathrm{Mg}, \mathrm{Cu}$ and $\alpha$-linoleic acid; these components may improve insulin sensitivity and lipid profiles $^{(76)}$. Beans are also an excellent source of nonnutritive constituents such as fibre, protease inhibitors, phytic acid, isoflavonoids, lignans and polyphenols such as tannins. These compounds have antioxidant, antimutagenic and anticarcinogenic activities and are also free radical scavengers ${ }^{(78-82)}$. In addition, capsaicin, the major pungent ingredient in red peppers, decreases the growth (e.g. inducing the apoptosis) of human and in vitro prostate cancer cells ${ }^{(83)}$, human leukaemic cells $^{(84)}$, gastric ${ }^{(85)}$ and hepatic carcinoma cells in vitro ${ }^{(86)}$. 
Finally, consumption of tomatoes has been found to have protective cardiovascular effects, with potential protection for prostate, oesophagus, stomach, lung and breast cancer $^{(87-89)}$.

One limitation of our study is the cross-sectional design of the NHANES III, which prevented us from drawing causal inferences. Dietary assessment tools also have inherent limitations. A serum level of nutrients and 1-month qualitative FFQ are not representative of individual nutrient intakes because of day-to-day variation in food consumption. However, serum levels of nutrients are an objective measure, and we included a proxy for contextual acculturation - i.e. neighbourhood density (percentage of Mexican-Americans at the census tract level) - that may capture other contextual factors related to the environment where Mexican-Americans live ${ }^{(25-28)}$.

The NHANES III questionnaire does not distinguish between traditional and non-traditional fruits (e.g. papaya or mango $v$. apricots) or other foods (e.g. corn tortillas $v$. corn muffins) among Mexican-Americans; this may lead to biased estimations or underestimations of some traditional foods in this population. In addition, NHANES III includes a mixed group of unprocessed-corn products such as bread or muffins but, with the exception of corn tortillas, does not include the consumption of processedcorn and specifically masa products that are essential foods in the diet of countries of Hispanic origin in the Americas. Masa is used to make tortillas (or tortillas chips), tamales, pozole, arepas and empanadas ${ }^{(90,91)}$. Masa is obtained after thermal-alkaline treatment, or a nixtamalization process, of the corn kernels. It involves lime-cooking (calcium hydroxide solution), followed by steeping for $12-16 \mathrm{~h}$, washing and stone-grinding the corn grains to produce masa. Cooking the corn with lime significantly increases its $\mathrm{Ca}(>700 \%), \mathrm{P}$ and Fe content ${ }^{(91)}$. Ca from masa acquires great relevance because it represents almost the only source of $\mathrm{Ca}$ in some Latin American countries. Masa products provide an important source of energy, proteins, dietary fibre, antioxidants and nutrients such as phytochemicals and carotenoids (e.g. lutein, zeaxanthin, $\beta$-cryptoxanthin ${ }^{(92)}$. However, limecooking affects the amount of resistant starch and the quality of protein. For example, the partial removal of the pericarp or bran leads to finished products that are considered as semi-whole grain foods ${ }^{(92)}$. Also, digestibility of the protein is decreased slightly, possibly because hydrophobic interactions, protein denaturation and crosslinking of proteins occur during maize processing that change the solubility of these components, which could affect amino acid release during enzymatic digestion ${ }^{(93)}$.

The Hispanic population is the largest minority group in the USA, and Mexican-Americans constitute the majority of this group. Isolated Mexican-American communities tend to maintain many of their traditional foods; however, public health campaigns are necessary not only to promote these traditional foods but also to make accessible other essential foods in their diet. On the other hand, more research is needed to assess potential health-protective effects of traditional Mexican-American foods such as avocados or specific kind of beans (e.g. pinto, black).

In conclusion, an increased percentage of MexicanAmericans at the census tract level was associated with less consumption of selective or non-traditional foods (e.g. some fruits such as melons, apples, berries; or vegetables such as broccoli) and low levels of serum Se and vitamin $\mathrm{C}$, but it was associated with more consumption of traditional foods such as corn products, legumes (beans, lentils and chickpeas), tomatoes and hot red chilli peppers. Thus, consumption of these traditional foods may make a difference to the health risk profiles in this population. Further studies are needed to determine if other nutrients or foods (e.g. masa products) that were not include in the data may influence dietary profiles in high-density Mexican-American neighbourhoods. Also, research is needed to explore whether unhealthier practices such as the consumption of fast foods or sedentary lifestyles are common among isolated Mexican-American neighbourhoods.

\section{Acknowledgements}

Sources of funding: The study was supported by research grants W81XWH-06-1-0290 from the Department of Defense and P50 CA10563-02 from the National Cancer Institute. The sponsors had no role in the design, methods, data collection, analysis, or manuscript preparation. The interpretation and reporting of these data are the sole responsibility of the authors. Financial disclosure: None of the authors has any conflict of interest related to this work. Author contributions: C.A.R.-O. and K.E. conducted the literature review. C.A.R.-O., H.J. and Y.-F.K. participated in the acquisition of data and provided statistical expertise. C.A.R.-O., K.E. and J.S.G. were responsible for supervision of the study and obtained funding. All authors participated in study conceptualization and design, interpretation of data, and editing the manuscript.

\section{References}

1. Lara M, Gamboa C, Kahramanian MI, Morales LS \& Hayes-Bautista DE (2005) Acculturation and Latino Health in the United States: a review of the literature and its sociopolitical context. Annu Rev Public Health 26, 367-397.

2. Williams DR \& Collins C (1995) US socioeconomic and racial-differences in health-patterns and explanations. Annu Rev Public Health 21, 349-386.

3. Arcia E, Skinner M, Bailey D \& Correa V (2001) Models of acculturation and health behaviors among Latino immigrants to the US. Soc Sci Med 53, 41-53.

4. Berry JW (1997) Immigration, acculturation, and adaptation. Appl Psychol 46, 5-34.

5. Hunt LM, Schneider S \& Corner B (2004) Should acculturation be a variable in health research? A critical 
review of research on US Hispanics. Soc Sci Med 59, 973-986.

6. Sampson RJ, Raudenbush SW \& Earls F (1997) Neighborhoods and violent crime: a multilevel study of collective efficacy. Science 277, 918-924.

7. Popkin BM, Duffey K \& Gordon-Larsen P (2005) Environmental influences on food choice, physical activity and energy balance. Psychol Behav 86, 603-613.

8. Cohen DA, Ashwood JS, Scott MM, Overton A, Evenson KR, Staten LK, Porter D, McKenzie TL \& Catellier D (2006) Public parks and physical activity among adolescent girls. Pediatrics 118, 1381-1389.

9. Frank LD, Sallis JF, Conway TL, Chapman JE, Saelens BE \& Bachman W (2006) Many pathways from land use to health - associations between neighborhood walkability and active transportation, body mass index, and air quality. J Am Plann Assoc 72, 75-87.

10. Moore LV \& Roux AVD (2006) Association of neighborhood characteristics with the location and type of food stores. Am J Public Health 96, 325-331.

11. Gordon M (1964) Assimilation in American Life. New York: Oxford University Press.

12. Massey DS (1985) Ethnic residential segregation: a theoretical synthesis and empirical review. Sociol Soc Res 69, 315-350.

13. Palloni A \& Arias E (2004) Paradox lost: explaining the Hispanic adult mortality advantage. Demography $\mathbf{4 1}$, 385-415.

14. Sorlie PD, Backlund E, Johnson NJ \& Rogot E (1993) Mortality by Hispanic status in the United States. JAMA $\mathbf{2 7 0}$, 2464-2468.

15. Hummer RA, Rogers RG, Nam CB \& LeClere FB (1999) Race/ethnicity, nativity, and US adult mortality. Soc Sci $Q$ 80, 136-153.

16. Singh GK \& Siahpush M (2002) Ethnic-immigrant differentials in health behaviors, morbidity and cause-specific mortality in the United States: an analysis of two national databases. Hum Biol 74, 83-109.

17. Eschbach K, Kuo YF \& Goodwin JS (2006) Ascertainment of Hispanic ethnicity on California death certificates: implications for the explanation of the Hispanic mortality advantage. Am J Public Health 96, 2209-2215.

18. Eschbach K, Stimpson JP, Kuo YF \& Goodwin JS (2007) Mortality of foreign-born and US-born Hispanic adults at younger ages: a re-examination of recent patterns. Am J Public Health 97, 1297-1304.

19. Elo IT, Turra CM, Kestenbaum B \& Ferguson RF (2004) Mortality among elderly Hispanics in the United States: past evidence and new results. Demography 41, 109-128.

20. Markides KS \& Coreil J (1986) The health of Hispanics in the southwestern United States: an epidemiologic paradox. Public Health Rep 101, 253-265.

21. Franzini L, Ribble JC \& Keddie AM (2001) Understanding the Hispanic paradox. Ethn Dis 11, 496-518.

22. Markides KS \& Eschbach K (2005) Aging, migration, and mortality: current status of research on the Hispanic paradox. J Gerontol B Psychol Sci Soc Sci 60B, Spec. No. 2, 68-75.

23. Aneshensel CS \& Sucoff CA (1996) The neighborhood context of adolescent mental health.J Health Soc Behav 37, 293-310.

24. LeClere F, Rogers RG \& Peters KD (1997) Ethnicity and mortality in the United States: individual and community correlates. Soc Forces 76, 169-198.

25. Eschbach K, Ostir GV, Patel KV, Markides KS \& Goodwin JS (2004) Neighborhood context and mortality among older Mexican Americans: is there a barrio advantage? $\mathrm{Am} \mathrm{J}$ Public Health 94, 1807-1812.

26. Eschbach K, Mahnken JD \& Goodwin JS (2005) Neighborhood composition and incidence of cancer among Hispanics in the United States. Cancer 103, 1036-1044.
27. Ostir GV, Eschbach K, Markides KS \& Goodwin JS (2003) Neighborhood composition and depressive symptoms among older Mexican Americans. J Epidemiol Community Health 57, 987-992.

28. Patel KV, Eschbach K, Rudkin L, Peek MK \& Markides KS (2003) Neighborhood context and self-rated health in older Mexican Americans. Ann Epidemiol 13, 620-628.

29. Bond Huie SA, Hummer RA \& Rogers RG (2002) Individual and contextual risks of death among race and ethnic groups in the United States. J Health Soc Behav 43, 359-381.

30. Inagami S, Borrell LN, Wong MD, Fang J, Shapiro MF \& Asch SM (2006) Residential segregation and Latino, black, and white mortality in New York City. J Urban Health 83, 406-420.

31. Cagney KA, Browning CR \& Wallace DM (2007) The Latino paradox in neighborhood context: the case of asthma and other respiratory conditions. Am J Public Health 97, 919-925.

32. Lee MA \& Ferraro KF (2007) Neighborhood residential segregation and physical health among Hispanic Americans: good, bad, or benign? J Health Soc Behav 48, 131-148.

33. Frank R, Cerda M \& Rendon M (2007) Barrios and burbs: residential context and health-risk behaviors among Angeleno adolescents. J Health Soc Behav 48, 283-300.

34. National Center for Health Statistics (1994) Plan and operation of the Third National Health and Nutrition Examination Survey, 1988-94. Series 1: Programs and collection procedures. Vital Health Stat 1 issue 32, 1-407.

35. Woteki CE, Briefel R, Hitchcock D, Ezzatfa T \& Maurer K (1990) Selection of nutrition status indicators for field surveys: the NHANES III design. J Nutr 120, 1440-1445.

36. National Center for Health Statistics (1997) National Health and Nutrition Examination Survey: NHANES III Data Files, Documentation, and SAS Code. http://www.cdc.gov/nchs/ about/major/nhanes/nh3data.htm (accessed April 2006).

37. United States Census Bureau (1991) US Census 1990. http://www.census.gov/main/www/cen1990.html (accessed April 2006).

38. Thompson FE \& Byers T (1994) Dietary assessment resource manual. J Nutr 124, Suppl., 2245S-2317S.

39. Kant AK (2002) Nature of dietary reporting by adults in the Third National Health and Nutrition Examination Survey, 1988-1994. J Am Coll Nutr 21, 315-327.

40. US Department of Health and Human Services, National Center for Health Statistics (1996) Third National Health and Nutrition Examination Survey, 1988-1994, NHANES II Laboratory Data File. CD-ROM, Series 11, No. 1A. Hyattsville, MD: Centers for Disease Control and Prevention.

41. Dixon LB, Sundquist J \& Winkleby M (2000) Differences in energy, nutrient and food intakes in a US sample of Mexican-American women and men: findings from the third National Health and Nutrition Examination Survey, 1988-1994. Am J Epidemiol 152, 548-557.

42. Shah M, Coyle Y, Kavanaugh A, Adams-Huet B \& Lipsky PE (2004) Focus group assessment of culturally specific cholesterol-lowering menus for Mexican Americans. Int Electron J Health Educ 7, 9-19.

43. Panel on Dietary Antioxidants and Related Compounds, Subcommittee on Upper Reference Levels of Nutrients and Interpretation and Uses of Dietary Reference Intakes \& the Standing Committee on the Scientific Evaluation of Dietary Reference Intakes (2000) Dietary Reference Intakes for Vitamin C, Vitamin E, Selenium, and Carotenoids. Washington, DC: National Academy Press.

44. World Cancer Research Fund/American Institute for Cancer Research (2007) Food, Nutrition, Physical Activity and the Prevention of Cancer: A Global Perspective. Washington DC: AICR; available at http://www.dietandcancerreport.org 
45. Gonzalez CA (2006) Nutrition and cancer: the current epidemiological evidence. BrJ Nutr 96, Suppl. 1, S42-S45.

46. Bazzano LA, He J, Ogden LG, Loria CM, Vupputuri S, Myers L \& Whelton PK (2002) Fruit and vegetable intake and risk of cardiovascular disease in US adults: the First National Health and Examination Survey Epidemiologic Follow-up Study. Am J Clin Nutr 76, 93-99.

47. Dauchet L, Amouyel P, Hercberg S \& Dallongeville J (2006) Fruit and vegetable consumption and risk of coronary heart disease: a meta-analysis of cohort studies. J Nutr $\mathbf{1 3 6}$, $2588-2593$.

48. He FJ, Nowson CA \& MacGregor GA (2006) Fruit and vegetable consumption and stroke: meta-analysis of cohort studies. Lancet 367, 320-326.

49. Skinner CN, Holt D \& Smith TMF (editors) (1989) Analysis of Complex Surveys. New York: John Wiley \& Sons, Inc.

50. Brogan D (2005) Sampling error estimation for survey data, Chapter XXI. http://unstats.un.org/unsd/HHsurveys/pdf/ Chapter_21.pdf (accessed June 2008).

51. Kawachi I \& Berkman LF (2003) Neighborhoods and Health. New York: Oxford University Press.

52. Lewis Munford Center (2000) Metropolitan Racial and Ethnic Change - Census 2000. http://mumford.albany.edu/ census/data.html (accessed August 2008).

53. Kant AK, Graubard BI \& Schatzkin A (2004) Dietary patterns predict mortality in a national cohort: The National Health Interview Surveys, 1987 and 1992. J Nutr 134, 1793-1799.

54. Kant AK, Schatzkin A, Graubard BI \& Schrairer C (2000) A prospective study of diet quality and mortality in women. JAMA 283, 2109-2115.

55. Liu S, Lee I-M, Ajani U, Cole SR, Buring JE \& Manson JE (2001) Intake of vegetables rich in carotenoids and risk of coronary heart disease in men: Physicians' Health study. Int J Epidemiol 30, 130-135.

56. Forman JP, Rimm EB, Stampfer MJ \& Curhan GC (2005) Folate intake and risk of incident hypertension among US women. JAMA 293, 320-329.

57. Hung H-C, Joshipura KJ, Jiang R, Hu FB, Hunter $\mathrm{D}$, Smith-Warner SA, Colditz GA, Rosner B, Spiegelman D \& Willett WC (2004) Fruit and vegetable intake and risk of major chronic disease. J Natl Cancer Inst 96, $1577-1584$.

58. Hu FB, Rimm EB, Stampfer MJ, Ascherio A, Spiegelman D \& Willett WC (2000) Prospective study of major dietary patterns and risk of coronary heart disease in men. $A m J$ Clin Nutr 72, 912-921.

59. Millen BE, Quatromoni PA, Nam B-H, O'Horo CE, Polak JF \& D'Agostino RB (2002) Dietary patterns and the odds of carotid atherosclerosis in women: the Framingham Nutrition Studies. Prev Med 35, 540-547.

60. Riboli E \& Norat $\mathrm{T}$ (2003) Epidemiologic evidence of the protective effect of fruit and vegetables on cancer risk. Am J Clin Nutr 78, Suppl., 559S-569S.

61. Vainio H \& Weiderpass E (2006) Fruit and vegetables in cancer prevention. Nutr Cancer 54, 111-142.

62. Pavia M, Pileggi C, Nobile CG \& Angelillo IF (2006) Association between fruit and vegetable consumption and oral cancer: a meta-analysis of observational studies. Am J Clin Nutr 83, 1126-1134.

63. Bodor JN, Rose D, Farley TA, Swalm C \& Scott SK (2008) Neighbourhood fruit and vegetable availability and consumption: the role of small food stores in an urban environment. Public Health Nutr 11, 413-420.

64. Crimmins EM, Kim JK, Alley DE, Karlamangla A \& Seeman T (2007) Hispanic paradox in biological risk profiles. $A m J$ Public Health 97, 1305-1310.

65. Turra CM \& Goldman N (2007) Socioeconomic differences in mortality among US adults: insights into the Hispanic paradox. J Gerontol B Psychol Sci Soc Sci 62, S184-S192.
66. Turra CM \& Elo IT (2008) The impact of salmon bias on the Hispanic mortality advantage: new evidence from Social Security data. Popul Res Policy Rev (online DOI 10.1007/ s11113-008-9087-4).

67. Guendelman S \& Abrams B (1995) Dietary intake among Mexican-American women: generational differences and a comparison with white non-Hispanic women. Am J Public Health 85, 20-25.

68. Montez JK \& Eschbach K (2008) Country of birth and language are uniquely associated with intakes of fat, fiber, and fruits and vegetables among Mexican-American women in the United States. J Am Diet Assoc 108, 473-480.

69. Mazur RE, Marquis GS \& Jensen HH (2003) Diet and food insufficiency among Hispanic youths: acculturation and socioeconomic factors in the third National Health and Nutrition Examination Survey. Am J Clin Nutr $\mathbf{7 8}$, $1120-1127$.

70. Sundquist J \& Winkleby M (2000) Country of birth, acculturation status and abdominal obesity in a national sample of Mexican American women and men. Int $J$ Epidemiol 29, 470-477.

71. Perez-Escamilla R \& Putnik P (2007) The role of acculturation in nutrition, lifestyle, and incidence of type 2 diabetes among Latinos. J Nutr 137, 860-870.

72. Unger JB, Reynolds K, Shakib S, Spruijt-Metz D, Sun P \& Johnson CA (2004) Acculturation, physical activity, and fast-food consumption among Asian-American and Hispanic adolescents. J Community Health 29, 467-481.

73. Galvez MP, Morland K, Raines C, Kobil J, Siskind J, Godbold J \& Brenner B (2008) Race and food store availability in an inner-city neighbourhood. Public Health Nutr 11, 624-631.

74. Kolonel LN, Hankin JH, Whittemore AS et al. (2000) Vegetables, fruits, legumes and prostate cancer: a multiethnic case control study. Cancer Epidemiol Biomarkers Prev 9, 795-804.

75. Correa P (1981) Epidemiological correlations between diet and cancer frequency. Cancer Res 41, 3685-3690.

76. Kabagampe EK, Baylin A, Ruiz-Narvaez E, Silesw X \& Campos H (2005) Decreased consumption of dried mature beans is positively associated with urbanization and nonfatal myocardial infarction. J Nutr 135, 1770-1775.

77. Hughes JS, Ganthavorn C \& Wilson-Sanders S (1997) Dry beans inhibit azoxymethane-induced colon carcinogenesis in F344 rats. $J$ Nutr 127, 2328-2333.

78. Diaz-Batalla L, Widholm JM, Fahey GC, Castano-Tostado E \& Paredes-Lopez O (2006) Chemical components with health implications in wild and cultivated Mexican common bean seeds (Phaseolus vulgaris L.). J Agric Food Chem 54, 2045-2052.

79. Espinosa-Alonso LG, Lygin A, Widholm JM, Valverde ME \& Paredes-Lopez O (2006) Polyphenols in wild and weedy Mexican common beans (Phaseolus vulgaris L.). J Agric Food Chem 54, 4436-4444.

80. Mazur WM, Duke JA, Wahala K, Rasku S \& Adlercreutz H (1998) Isoflavonoids and lignans in legumes: nutritional and health aspects in humans. Nutr Biochem 9, 193-200.

81. Midorikawa K, Murata M, Oikawa S, Hiraku Y \& Kawanishi S (2001) Protective effect of phytic acid on oxidative DNA damage with reference to cancer chemoprevention. Biochem Biophys Res Commun 288, 552-557.

82. Gonzales de Mejia E, Castano-Tostado E \& Loarca-Pina G (1999) Antimutagenic effects of natural phenolic compounds in beans. Mutat Res Genet Toxicol Environ Mutagen 441, 1-9.

83. Mori A, Lehmann S, O'Kelly J, Kumagai T, Desmond JC, Pervan M, McBride WH, Kizaki M \& Koeffler HP (2006) Capsaicin, a component of red peppers, inhibits the growth of androgen-independent, p53 mutant prostate cancer cells. Cancer Res 66, 3222-3229. 
84. Ito K, Nakazato T, Yamato K, Miyakawa Y, Yamada T, Hozumi N, Segawa K, Ikeda Y \& Kizaki M (2004) Induction of apoptosis in leukemic cells by homovanilic acid derivative, capsaicin, through oxidative stress. Implications of phosphorylation of $\mathrm{p} 53$ at ser- 15 residue by reactive oxygen species. Cancer Res 64, 1071-1078.

85. Kim JD, Kim JM, Pyo JO, Kim SY, Kim BS, Yu R \& Han IS (1997) Capsaicin can alter the expression of tumor formingrelated genes which might be followed by induction of apoptosis of a Korean stomach cancer cell line, SNU-1. Cancer Lett 120, 235-241.

86. Jung MY, Kang HJ \& Moon A (2001) Capsaicin-induced apoptosis in SK-Hep-1 hepatocarcinoma cells involves Bel2-down-regulation and caspase-3 activation. Cancer Lett 165, 139-145.

87. O'Kennedy N, Crosbie L, van Lieshout M, Broom JI, Webb DJ \& Duttaroy AK (2006) Effects of antiplatelet components of tomato extract on platelet function in vitro and ex vivo: a time-course cannulation study in healthy humans. $A m \mathrm{~J}$ Clin Nutr 84, 570-579.

88. Muller N, Alteheld B \& Stehle P (2003) Tomato products and lycopene supplements: mandatory components in nutritional treatment of cancer patients? Curr Opin Clin Nutr Metab Care 6, 657-660.

89. Giovannucci E, Rimm EB, Liu Y, Stampfer MJ \& Willett WC (2002) A prospective study of tomato products, lycopene and prostate cancer risk. J Natl Cancer Inst 94, 391-398.

90. Bello-Perez LA, Osorio-Diaz P, Agama-Acevedo E, SolorzaFeria J, Toro-Vazquez JF \& Paredes-Lopez O (2003) Chemical and physicochemical properties of dried wet masa and dry masa flour. J Sci Food Agric 83, 408-412.

91. Martinez-Flores HE, Figueroa JDC, Martinez-Bustos F, Gonzalez-Hernandez J, Rodriguez Garcia ME, Banos Lopez AML \& Garnica-Romo MG (2002) Physical properties and composition of femurs of rat fed with diets based on corn tortillas made from different processes. Int J Food Sci Nutr 53, 155-162.

92. De la Parra C, Serna Saldivar SO \& Liu RH (2007) Effect of processing on the phytochemical profiles and antioxidant activity of corn for production of masa, tortillas, and tortilla chips. J Agric Food Chem 55, 4177-4183.

93. Food and Agricultural Organization of the United Nations (1992) Maize in human nutrition. http://www.fao.org/ docrep/t0395e/t0395e07.htm (accessed October 2008). 